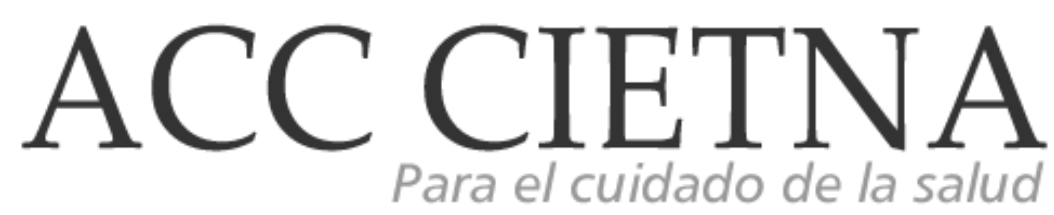

https: / / doi.org/10.35383/cietna.v2i2.140

\title{
Análisis de la interacción enfermero - cuidador principal. Servicio de Geriatría. Hospital Nacional Almanzor Aguinaga Asenjo. Chiclayo $-2013$
}

\author{
Monteza Saldaña Anny Lizet ${ }^{1}$, Lázaro Alcántara Elaine ${ }^{2}$
}

\begin{tabular}{l} 
INFORMACIÓN DEL ARTÍCULO \\
\hline Historia del artículo: \\
Recibido el 12 de mayo de 2015 \\
Aceptado el 15 de noviembre de 2015
\end{tabular}

Palabras claves:

Comunicación

Interacción

Enfermero

Cuidador principal

\section{RESUMEN}

La investigación tuvo como objetivo analizar y comprender la interacción que existe entre el enfermero y cuidador principal del paciente geriátrico; la investigación se desarrolló en el servicio de Geriatría del Hospital Nacional Almanzor Aguinaga Asenjo (H.N.A.A.A.). Las bases conceptuales se tomaron de la teoría de King (1984). La metodología fue cualitativa, con abordaje de estudio de caso según Andrade (2006); los sujetos de investigación fueron 5 enfermeras y 7 cuidadores; utilizándose la entrevista semiestructurada como técnica de recojo de información. La muestra se determinó por saturación y redundancia. Los datos fueron tratados con análisis de contenido propuesto por Berelson (1994) y se respetaron los criterios de rigor científico y principios de la ética personalista. Los resultados fueron organizados en dos categorías: (1) el primer contacto: definiendo roles para la interacción y (2) la buena comunicación para el logro de una meta. La interacción entre enfermera y cuidador principal se produce a partir de la percepción que se genera en un primer contacto, definiendo y (re)definiendo roles, asumiendo la enfermera un rol de educadora y el cuidador un rol de ayuda por lo que el cuidado se convierte en un proceso de comunicación para el logro de la pronta recuperación del paciente.

\footnotetext{
${ }^{1}$ Licencida en Enfermería. Enfermera con trabajo independiente, Chiclayo, Perú. Email: xxxx@usat.edu.pe

. ${ }^{2}$ Magister en Enfermería. Licenciada en Enfermería. Docente en la Escuela de Enfermería de la Universidad Católica Santo Toribio de Mogrovejo, Chiclayo, Perú. Email: elazaro@usat.edu.pe
} 
Analysis of interaction nurses - primary caregiver. Geriatric Department. Hospital Almanzor Aguinaga Asenjo. Chiclayo - 2013

ABSTRACT

Keywords:

Communication

Interaction

Nurse

Primary caregiver
The research aimed to analyze and understand the interaction between the geriatric patient's nurse and primary caregiver; research developed in the Geriatric Service Almanzor Aguinaga Asenjo National Hospital. The conceptual bases were supported in the theory of Imogene King (1984). The methodology was qualitative, with case study approach according Andrade (2006), the research subjects were 5 nurses and 7 caregivers; using the semi-structured interview as information gathering technique. The sample was determined by saturation and redundancy. Data were treated with content analysis (Berelson 1994) and the criteria of scientific rigor and the principles of personalist ethics were respected. The results were organized into two categories: (1) First contact: defining roles for interaction and (2) good communication to achieve a goal. The interaction between nurse and primary caregiver comes from the perception that is generated in a first contact, defining and (re) defining roles, thereby the nurse assumes an educator role and the caregiver a support role so care becomes a process of communication to achieve the speedy recovery of the patient.

\section{Introducción}

Las intervenciones de enfermería se dirigen tanto a la persona cuidada como a su entorno y constituyen un elemento fundamental la labor de apoyo que brinda a la familia $y$ al cuidador principal. El profesional de enfermería idealmente debería establecer una auténtica relación de ayuda, con la persona (paciente), sino también con quien asume el rol de cuidador principal (a menudo oculto) ${ }^{1}$.

El cuidador principal es una persona que está viviendo una situación compleja. Por razones de roles familiares, económicos, culturales y otros, esta persona tiene la exigente tarea de cuidar de un familiar enfermo y con diferentes grados de dependencia, situación que le genera emociones contradictorias; por un lado, en la mayoría de los casos el cuidador principal quiere cuidar del familiar; pero por otro, siente rabia, molestia e impotencia, porque esta tarea le roba autonomía y es de mucha responsabilidad y trabajo. El cuidador tenía organizada su vida en torno a sus actividades cotidianas y ahora tiene que cambiarla completamente para añadir esta tarea.

Culturalmente en nuestro país, hay una gran presión para que las mujeres sean las cuidadoras principales, en la mayoría de los casos, las hijas. Si ellas, no cuidan de su madre o padre enfermo, se le ve como una "mala hija". Aún es un tabú el admitir que uno no puede o quiere cuidar de su padre o madre. ${ }^{2}$

Por otro lado, en los diferentes campos clínicos en los que se forman los estudiantes de enfermería, se observa que no existe una buena interacción 
entre el cuidador principal y el profesional enfermero, que las relaciones entre ambos son distantes, coincidiendo incluso con algunos estudios ya realizados; situación que llevó a plantearse el problema de investigación: ¿Cómo es la interacción del enfermero y cuidador principal del paciente geriátrico en el Servicio de Geriatría del H.N.A.A.A.?

La investigación tuvo como objeto de estudio: la interacción del enfermero y cuidador principal. Los objetivos fueron: analizar y comprender la interacción que existe entre el enfermero y cuidador principal del paciente geriátrico en el Servicio de Geriatría del H.N.A.A.A.

Varias investigaciones de enfermería con relación al cuidado se han enfocado en el sujeto con problemas de salud, más no en la interacción que el acto de cuidar demanda del enfermero y del cuidador principal, por lo que las autoras de esta investigación creyeron necesario profundizar en la "interacción" como proceso inmerso en la relación de ayuda en el cuidado, utilizando como base conceptual la perspectiva teórica de King.

El análisis de la interacción entre enfermero y cuidador principal es una temática relevante para potenciar la práctica del profesional de enfermería, pues a través de esta investigación se demostró la importancia de que el enfermero adquiera habilidades $y$ actitudes fundamentales que le permitan iniciar una relación de ayuda de forma eficiente.

La familia de una persona adulta mayor hospitalizada se ha convertido en un elemento cada vez más activo en el cuidado. En este sentido, el enfermero debe interactuar con cada uno de ellos buscando su ayuda para recuperar la salud e integridad del paciente ${ }^{3}$.

La investigación contribuye a la comprensión de todos aquellos factores de cuidado que favorecen o limitan la interacción entre el enfermero y el cuidador principal del adulto mayor hospitalizado y viceversa, pues al analizar las formas de interacción del enfermero con el cuidador principal, se reflejan aquellos factores que facilitan y limitan el cuidado. ${ }^{3}$

La utilización de la teoría del logro de objetivos de Imogene King se configura en un valioso aporte para la ciencia y práctica de enfermería en una perspectiva descriptiva, toda vez que existe una escasa producción de trabajos que apliquen los conceptos y modelos inmersos en esta teoría.

\section{Metodología}

La investigación fue de tipo cualitativa, de abordaje estudio de caso. Esta metodología permitió dar respuesta al problema de estudio, explicando con los resultados un fenómeno poco estudiado. Representó un buen instrumento metodológico para obtener información veraz, partiendo de las percepciones tanto de enfermeros como de cuidadores principales. Se obtuvo una cualificada información de la propia realidad de la interacción, desde el interior de la misma ${ }^{4}$.

Los sujetos lo constituyeron 5 enfermeros, con una experiencia clínica mayor de dos años, además 7 cuidadores principales de los adultos mayores, todas ellas familiares que hayan cuidado al paciente geriátrico por más de 6 meses en su casa y durante su estancia hospitalaria. La muestra se seleccionó por conveniencia y fue delimitada, según criterios de saturación y redundancia 5 .

Se pudo apreciar que los cuidadores principales mayormente son de sexo femenino, entre las 51 a 60 años y presentan una estancia hospitalaria mayor de 16 días; por otro lado las enfermeras en su totalidad son de sexo femenino y oscilan entre 31 a 40 años.

Los datos se recolectaron mediante la entrevista semiestructurada, la misma que constó de dos partes: la primera donde se registraron los datos generales, que permitieron caracterizar a los sujetos de estudio; la segunda constó de 6 
preguntas para el cuidador principal y 4 preguntas para el profesional enfermero, las cuales estuvieron orientadas a conocer la interacción que existe entre ambos sujetos, formuladas en función a la teoría de Imogene King6.

En esta investigación se empleó para el análisis de datos, el análisis de contenido ${ }^{7}$, teniendo en cuenta las siguientes etapas: descripción, análisis e interpretación. En la fase de descripción, la investigadora se familiarizó con los datos realizando la revisión completa de los audios tratando de captar no solo las palabras, sino también los sentimientos, percepciones, énfasis, de los sujetos de estudio, los cuales fueron importantes en la interpretación del mensaje. Una vez realizadas las 5 entrevistas a las enfermeras y las 7 a los cuidadores principales, se procedió a la transcripción de los discursos, lectura y relectura respectiva, para familiarizarse con el contenido de los mismos, buscando obtener el mensaje de fondo de los mismos. Es así como se encontraron 51 unidades significativas en relación al objeto de estudio.

En la fase de análisis e interpretación, los investigadores se centraron en la comprensión de los datos y la explicación del fenómeno en estudio, llegando a conocer e interpretar la realidad encontrada. Es así que el análisis de contenido consistió en determinar los pasos para el tratamiento de los datos obtenidos, reducir, categorizar, clarificar y comparar la información mediante la lectura y relectura de los discursos para comprender los resultados de la información y dar respuesta al problema planteado en la presente investigación 8 .

Durante el desarrollo de la investigación también se consideraron y pusieron en práctica los siguientes principios éticos: respeto a la vida humana y el de libertad y subsidiaridad. Aquí las enfermeras y los cuidadores principales participaron de manera libre, previa firma del consentimiento informado, además de la utilización de códigos como: E1, E2, E3...etc para las enfermeras y CP1, CP2, CP3 ...etc para los cuidadores principales y así proteger su identidad, demostrando en todo momento respeto a su dignidad como ser humano, para finalmente poder publicar la información obtenida bajo el anonimato ${ }^{9}$.

Así mismo se tuvieron en cuenta los criterios de rigor científico, con el propósito de asegurar la objetividad de la información y aumentar la calidad de esta.

\section{Resultados, análisis y discusión}

Después de la recolección y tratamiento de datos, se dio inicio al análisis minucioso de los mismos, de los cuales se obtuvieron 2 categorías que permitieron el ordenamiento y comprensión de la información referida al objeto de estudio. Las cuales se presentan a continuación:

I. El primer contacto: definiendo roles para la interacción.

II. La buena comunicación para el logro de una meta.

\section{El primer contacto: definiendo roles para la interacción.}

En esta categoría se pretende discutir la importancia que tiene para los cuidadores principales y los enfermeros, la percepción en el primer contacto para poder definir los roles $y$ llegar a interactuar. La percepción es la representación de la realidad que cada persona genera a partir de la conciencia de lo que le rodea.

Solo segundos suelen bastar para formarse una percepción de la persona que se acaba de conocer, y se tiende a utilizar esa percepción para juzgar a dicha persona. En este sentido, cuando la enfermera tiene un primer contacto con el cuidador principal familiar, genera una imagen en ellos, que marcará la pauta inicial de la interacción. Como lo podemos notar en los siguientes 
discursos de cuidadores principales y enfermeras con 0 a 7 días de estancia hospitalaria.

“...Cuando un paciente ingresa al servicio no te ayuda, quiere que todo lo haga la enfermera y el técnico, ellos (cuidadores principales) solo están mirando..." E2

“...Cuando el cuidador principal ingresa a este servicio es como un paciente más..."E3

En el contexto del primer contacto, durante los primeros días de estancia hospitalaria, la enfermera percibe al cuidador principal como una "carga" para su trabajo. Las percepciones son importantes puesto que lo que se deduce sobre el otro, en cuanto a pensamientos y sentimientos, tienden a determinar los comportamientos $y$ reacciones hacia la persona.

Las percepciones, al ser valoradas o juzgadas, son la base del subsiguiente patrón de la interacción.

Durante esta fase, ambos empiezan a establecer un enlace ${ }^{1}$.

Cuando la enfermera tiene un primer encuentro con el cuidador principal familiar, los sentimientos de sobrecarga laboral emergen como resultado de las percepciones desarrolladas en ese momento, pero que pueden cambiar con el interactuar cotidiano entre ambos sujetos. Por otro lado, los cuidadores principales familiares emiten los siguientes discursos en relación a la percepción que formó en un primer contacto:

“...Cuando ingresé a este servicio, la enfermera vino un ratito a ver a mi papá y después se fue... solo me saludó y no me dijo nada..." CP1

"...La primera vez que vino la enfermera, solo vio el medicamento y se fue..." CP6

La percepción que el cuidador principal familiar se generó de la enfermera en los primeros días de estancia hospitalaria, Se basa en que ella no dispone de tiempo para interactuar.
Las enfermeras deben mantener, aunque tengan múltiples labores, las virtudes de comunicación con el otro para ayudarlo y sostenerlo en esta difícil etapa de su vida. El alejamiento de la enfermería del buen cuidado, se debe a que la enfermera muchas veces dedica todo su tiempo a las técnicas, procedimientos y supervisiones $u$ otros aspectos también importantes de su quehacer.

La atención de estos aspectos debe ser complementaria y no contraria ${ }^{12}$.

Una persona podría emitir un juicio de alguien siempre y cuando haya tenido contacto con ella, de lo contrario la percepción que tendría será estereotipada porque ambos sujetos no interactuaron. En referencia a ello los siguientes discursos reflejan la interacción de la enfermera y el cuidador principal después de 8 a 15 días de estancia hospitalaria, en la que ya entablaron un contacto el uno con el otro y se mejora notablemente la percepción de ambos:

“...Muchas veces pensamos que el cuidador viene solo para acompañar al paciente, pero luego cuando conversamos, vemos que este ayuda en el cuidado y que se llega tanto a sensibilizar, que ayuda a otros cuidadores..."El

“..A veces los cuidadores ya han estado en otro servicios y vienen educados, ellos cambian la forma de pensar, no son pacientes agregados, al contrario ayudan a cuidar..."E5

Con el transcurrir de la estancia hospitalaria, el profesional enfermero y el cuidador principal van analizándose paulatinamente con la información que perciben del otro, de esta manera se puede obtener una percepción veraz de enfermeracuidador principal y viceversa. Este supuesto se sustenta en los siguientes relatos de los cuidadores principales:

“...Cuando yo ingresé a este servicio, tenía otro 
concepto de la enfermera, pensaba que era amargada y que no conversaba con nadie, pero luego comprobé que no solo coloca el medicamento si no que conversa conmigo, me enseña, pregunta por mi paciente; entonces me di cuenta que ellas a pesar que están muy ocupadas, se preocupan por nosotros, te conversan..." CP4

\section{“...Yo pensaba que la mayoría de enfermeras son} coléricas y que no se preocupan por el paciente, pero las de aquí (servicio de Geriatría H.N.A.A.A son muy amables $y$ atentas... y como llevo varios días aquí, ya las conozco a cada una... "CP2

En estos discursos se observa que conforme pasa el tiempo los cuidadores principales manifiestan una serie de cualidades de la enfermera del servicio de Geriatría, es decir, está describiendo cómo es que percibe ahora a la enfermera y cómo lo percibía antes, esto lo pueden hacer porque tienen una estancia hospitalaria mayor a una semana $y$ ha tenido tiempo para observar $y$ analizar paulatinamente al profesional enfermero y valorar su labor como cuidadora.

Se deduce entonces que la percepción, en un primer contacto, es la representación interna de lo que sucede en el exterior, al modo de hipótesis; y es única en cada persona. La percepción real se puede dar siempre y cuando haya una interacción, de no ser así, la percepción que se tiene será estereotipada, como se puede evidenciar en el primer contacto entre cuidadores principales y enfermeros en el Servicio de Geriatría, cuando la relación va cambiando conforme interactúan así, la interacción es la única manera para que ambos sujetos tengan una percepción real uno del otro que les permita asumir y cumplir sus roles.

Cuando alguien pregunta ¿Quién eres?, contesta diciendo: "soy una enfermera, una maestra, un ingeniero, un cuidador". Si es así, está respondiendo en términos del rol. Como lo mencionan las enfermeras en los siguientes discursos.
“...A veces voy por cada unidad a la hora del alimento, yo estoy observando cómo lo está haciendo, y si veo que lo está haciendo mal y tengo la oportunidad de intervenir y enseñarle, lo hago. Por ahí le estoy diciendo que ese es su rol, es decir darle de comer a su paciente de una forma adecuada..."E2

“... Aquí los cuidadores principales son de mucha ayuda, cumplen un rol de ayuda, ya que nosotros no podemos estar todo el turno con los pacientes..." El

En la descripción de estos testimonios, se puede apreciar que el enfermero percibe su rol hacia el cuidador principal como un educador y el del cuidador como un rol de ayuda. El marco para la función educadora es el proceso de enseñanza aprendizaje, dentro de este marco, el profesional de enfermería evalúa las necesidades de aprendizaje, planea y pone en marcha los métodos de enseñanza para satisfacer esas necesidades y evalúa la eficacia de la enseñanza. Para ser un educador eficaz, el profesional de enfermería debe tener habilidades interpersonales eficaces $y$ familiarizarse con los principios del aprendizaje del cuidador ${ }^{13}$.

Los roles son creaciones sociales, es decir, la forma cómo se relacionan los individuos y las instituciones, las cuales son otra creación social. Las principales instituciones son la familia, la educación, la religión, la política (el Estado) y la economía. Estas instituciones sociales poseen unas normas implícitas que los individuos aceptan y asimilan, de lo contrario, pueden ser rechazados 0 , incluso, expulsados del grupo ${ }^{14}$.

Pero ¿qué puede influir en un cuidador principal para que pueda percibir y desarrollar su rol? Un factor que puede influenciar en el rol es el estrés, que es un estado dinámico por medio del cual un ser humano interactúa con el medioambiente para mantener el equilibrio necesario y de esta manera, desarrollarse y desempeñar funciones. Esto implica un intercambio de energía e información 
entre la persona y el medioambiente para regular y controlar los causantes de estrés. Respecto a esto, las enfermeras manifiestan:

“...El cuidador principal muchas veces al inicio no te ayuda, está tenso, estresado porque, imagínate, su familiar está enfermo y además ha dejado su casa para ahora estar todo el día en el hospital. Lo único que quiere es que su familiar se reestablezca y vaya a casa con él..." El

“...El cuidador principal, cuando se estresa, no te ayuda en nada, parece que está en su mundo y a veces se torna agresivo..." E3

El estrés es una reacción fisiológica del organismo en el que entran en juego diversos mecanismos de defensa para afrontar una situación que se percibe como amenazante o de demanda incrementada ${ }^{15}$. El estrés es la respuesta de energía de un individuo a personas, objetivos y acontecimientos que lo producen. Cuando hay mucho estrés en los individuos que quieren interactuar, su campo perceptual disminuye y su toma de decisiones es menos eficaz.

Estos factores pueden llevar a menos interacciones, poca fijación de roles y además a hacer menos efectivo el cuidado del paciente. Como se refleja en estas disertaciones, el cuidador principal muchas veces refleja estrés al momento de ingresar al servicio, su estado no le permite tener una buena percepción de su entorno, ni una comunicación con la enfermera, por lo tanto no puede diferenciar o definir bien su rol dentro del nuevo ambiente en el que se encuentra.

El estrés es una respuesta adaptativa del organismo ante situaciones de alarma y tiene su origen en la zona límbica del cerebro, cuando las señales de alarma percibidas son de distinto tipo, la dificultad de discriminar la respuesta adecuada hace que predomine la más potente en ese momento, y es posible que no sea la que el cuidador deseaba exhibir ${ }^{16}$.

\section{La buena comunicación para el logro de una meta}

En esta categoría abordaremos el segundo momento del proceso de interacción, en el que ambos sujetos después de percibirse, conocerse y establecer el rol que deben desarrollar, entablan una comunicación constante que está orientada al logro de una meta y si esta se logra, es porque ocurrió una buena interacción.

El cuidado de enfermería implica conocimiento de la comunicación para interactuar con individuos muy diversos. Por ejemplo, la manera como los enfermeros entran a la habitación de un adulto mayor hospitalizado lleva un mensaje. La enfermera que se para en la puerta de la habitación puede estar comunicando un mensaje que el cuidador principal interpreta como "está ocupada para entrar en la habitación".

Podemos hablar de comunicación para referirnos tanto a la acción como al efecto de comunicar. La comunicación implica algún tipo de relación o de unión entre dos partes, que se conectan o se corresponden entre sí, de algún modo. Podemos definirla como un proceso de transmisión y recepción de señales, ideas, mensajes, datos, mediante un código, un sistema de signos y de reglas que es común tanto al emisor como al receptor ${ }^{17}$.

Según las siguientes manifestaciones del profesional enfermero, existe algún tipo de comunicación entre ambos sujetos.

“...Yo me comunico con el cuidador y con el paciente, desde el momento que ingreso, al momento del saludo, al momento de preguntarle ¿Cómo está?, ¿Cómo está su paciente? En el momento del tratamiento, le estoy aplicando su medicamento y ellos están preguntando o yo estoy preguntando ¿cómo paso la noche...?." E5

“...Yo cuando hablo o le enseño algo al cuidador principal, me aseguro que éste, haya comprendido 
lo que le he dicho, evaluándolo, haciendo que haga lo que le he enseñado..." E4

De estos discursos se puede deducir que existe interacción entre el enfermero y cuidador principal, y ésta se da al momento del tratamiento, donde la enfermera tiene la oportunidad de estar más cerca tanto del paciente como de su cuidador.

Para lograr una comunicación efectiva, no sólo se requiere conocer el proceso de la comunicación de una manera integral, sino establecer mecanismos que garanticen que el mensaje que queremos transmitir llegue de una manera correcta al receptor y que a través de la retroalimentación podamos asegurarnos que el mensaje fue recibido con éxito. Este aspecto es importante en la estrategia de comunicación, ya que la efectividad en la transmisión del mensaje que involucre los elementos de integración e interacción es fundamental en la construcción de una visión compartida que oriente los esfuerzos hacia los mismos objetivos tanto organizacionales como personales ${ }^{18}$.

Un factor muy importante que dificulta el interactuar entre enfermera y cuidador principal es la sobrecarga laboral, debido a que la enfermera tiene múltiples labores que debe cumplir en un solo turno que la dificultan para que en un primer momento pueda conocer al cuidador principal, brindarle educación, establecerle roles y llegar a una meta, como lo podemos ver en los siguientes discursos:

“...A veces es difícil tener mucha comunicación con el paciente y el cuidador principal, ya que hay una sola enfermera para todos los pacientes, si por ejemplo tenemos una emergencia, nos demanda mucho tiempo y ya no se puede interactuar en un turno..." E2

“...Es muy difícil tener una comunicación fluida con el familiar porque tenemos que hacer tantas cosas en un turno de seis horas, nos dedicamos a dar tratamiento, curar úlceras por presión, hacer notas, actualizar el kardex, en fin son tantas las labores de enfermería..." El

Estos discursos develan que muchas veces no se puede tener una adecuada comunicación e interacción con el cuidador principal por la sobrecarga laboral al que el profesional de enfermería está sometido.

Después de percibir a la otra persona, los individuos constituyen su propia realidad, la cual se basa en sus percepciones únicas, para definir su rol y poder interactuar. Estos individuos que están comunicándose, están en el proceso de interacción y pueden identificar de manera mutua los objetivos y los medios para alcanzarlo. Si ambos están de acuerdo con los medios para obtenerlos están realizando transacciones para lograr una meta. El establecimiento de objetivos específicos, la retroalimentación sobre el avance hacia las metas y el reforzamiento de una conducta deseada estimulan la motivación y requieren comunicación.

Si partimos de la base de que la meta compartida es fundamental en el logro de objetivos, entonces, podemos establecer que el proceso de comunicación de esa meta es eficiente. Tal como se aprecia en los siguientes discursos:

\section{"...a veces hemos tenido adultos mayores que} llegaron bastante mal, estuvieron postrados varias semanas y cuando salen no tienen ninguna úlcera por presión... ahí se ha logrado una meta, se nota que hay un trabajo en conjunto, nosotras le hemos enseñado al cuidador principal que debe cambiarlo de posición cada dos horas y este lo ha hecho muy bien..." E4

“...si el cuidador principal se compromete a tener un buen cuidado para que su paciente se restablezca, pone atención a todo lo que nosotras le enseñamos, está pendiente de su familiar, de seguro su paciente se reestablece rápidamente... "E5 
A través de las percepciones del medioambiente $y$ la comunicación verbal y no verbal, los individuos interactúan de diversas maneras. Algunas de estas interacciones conducen a transacciones, estas se definen como interacciones que tienen por objetivo principal el logro de un propósito o fin determinado.

Para King ${ }^{6}$, las personas interactúan y tienen una meta en común, están en una transacción. Esta es la conducta observable de seres humanos que interactúan con su medioambiente. Las transacciones son consideradas como el componente de la valoración de interacciones humanas. Si las enfermeras y los cuidadores principales hacen transacciones para el cuidado de los pacientes, ellos se comunican para poder intercambiar sus puntos de vista. Esto requiere ponerse de acuerdo, tratos e intercambio social.

Cuando las enfermeras y los cuidadores principales comparten su marco de referencia acerca de los eventos actuales, identifican denominadores comunes, mediante los cuales pueden fijar metas comunes. Cuando las transacciones las hacen en coordinación enfermera y cuidador principal, se alcanzan las metas. Las expectativas y desempeño del rol, tanto de la enfermera como del cuidador principal, influyen en las transacciones ${ }^{19}$.

\section{Conclusiones}

1. La interacción es un proceso de percepción y comunicación, manifestado por conductas verbales y no verbales que están orientadas al logro de objetivos. Los aspectos que muchas veces limitan esta interacción en el profesional enfermero es la sobrecarga laboral debido a que este realiza múltiples actividades en un solo turno.

2. La percepción que tiene el cuidador principal de la enfermera y viceversa está estereotipada, ya que en las primeras horas de estancia hospitalaria, estas percepciones son influenciadas con experiencias pasadas. Mientras más días de estancia hospitalaria tenga el cuidador principal, hay mayor oportunidad de que se establezca mayor interacción entre ambos sujetos, la misma que favorece el conocimiento de sí mismos como seres humanos únicos, llegando a producirse una percepción real de ambos.

3. Para el profesional de enfermería, el estrés influye de manera negativa en la interacción, los cuidadores principales que estén bajo estos síntomas difícilmente podrán interactuar de una manera adecuada y por lo tanto no conocerán las expectativas que se tiene de su rol, para así poder desempeñarlo y lograr metas.

4. La estancia hospitalaria es relevante, ya que mientras más tiempo tenga el cuidador principal familiar, menor será sus manifestaciones de estrés debido a que ya se siente familiarizado con el ambiente y así podrá desempeñar adecuadamente su rol y por lo tanto alcanzar las metas junto con la enfermera.

5. El conocimiento y las habilidades de comunicación especiales constituyen el principal reto de las enfermeras para lograr una buena interacción con los cuidadores principales y así establecer roles y alcanzar metas trazadas.

6. Un factor muy importante que dificulta la interacción entre enfermera y cuidador principal es la sobrecarga laboral, debido a que la enfermera tiene múltiples labores que debe cumplir en un solo turno y son estas las que dificultan que en un primer momento se pueda llegar a conocer al cuidador principal, brindarle educación, establecer roles y llegar a una meta.

7. El profesional de enfermería recalca la importancia de la educación a los cuidadores principales para su correcto desempeño con sus pacientes. En su papel de educadora la enfermera considera que es importante además de brindar la educación evaluar si los procedimientos fueron aprendidos. 
8. La interacción entre enfermera y cuidador principal se produce a partir de la percepción que se genera en un primer contacto, definiendo y (re)definiendo roles, asumiendo la enfermera un rol de educadora y el cuidador, un rol de ayuda, por lo que el cuidado se convierte en un proceso de comunicación para el logro de la pronta recuperación del paciente.

\section{Bibliografía}

1. Villar R., Pancorbo P., Jiménez M., Cruz A., García P. Qué hace el cuidador familiar en el hospital: Cómo se ve a sí mismo y cómo lo ven los profesionales. Gerokomos [revista en la Internet]. 2012 Mar [citado 2012 Ago 25]; 23(1):7-14. Disponible en:

http:// scielo.isciii.es/scielo.php?script=sci_arttex t\&pid $=$ S1 134928

2. Delicado M., Candel E., López A. Interacción de enfermería y cuidadoras informales de personas dependientes. Atención primaria: Publicación oficial de la Sociedad Española de Familia y Comunitaria, ISSN 0212-6567, Vol. 33, №. 4, 2004, págs. 193-199.

3. Vidal R., Adamuz J., Feliu P. Relación terapéutica: el pilar de la profesión enfermera. Enferm. glob. [revista en la Internet]. 2009 Oct [citado 2012 Sep 19]; (17): Disponible

en:

http:/ / scielo.isciii.es/scielo.php?script=sci_arttex t\&pid=S169561412009000300021\&lng=es.

4. Mejías M. Interacción del personal de Enfermería con los familiares del paciente Politraumatizado y su relación con el nivel de estrés de los familiares. Venezuela: [revista en la Internet]. 2010 Jul [citado 2012 Sep21];(17): Disponible en: http:/ / www.salamandra.edu.co/fileadmin/docum entos/articulos_academicos/Enfemeria.pdf.

5. Potter P., Perry, A. Fundamentos de Enfermería. Volumen I. 5 a edición. España: editorial Océano; 2004.
6. King I. Enfermería como profesión: Filosofía, principios y objetivos. México: Editorial Limusa, S.A; 1984.

7. Minayo M. Pesquisa social. Teoría, método e creatividad. Petrópolis: Vocês; 1994.

8. Hernández R., Fernández C. Metodología de la investigación. 4ta edición. México: Mc- Hill Interamericana; 2006.

9. Sgreccia E. Bioética personalista. Modelo personalista cualitativa. Cali. Disponible en: http//

colombiamedica. Univalle.edu.pe/Vol34No03/ cm34n3alo .htm.

10. De Andrade G. Estudo de caso: uma estrategia de Pesquisa. Sao Paulo: Atlas; 2006.

11. Álvarez G. La percepción de la organización: clave para la comprensión del individuo en la organización. Revista interamericana de Psicología Ocupacional. Vol.11, números 1 y 2, 1992.

12. Poblete $\mathrm{M}$; Valenzuela, S. Cuidado humanizado: un desafío para las enfermeras en los servicios hospitalarios. Acta Paul. Enferm; 2007.

13. Palomino A. Fundamentos de Psicología de la personalidad. 1 er edición. Madrid: Editorial: ediciones Rialp; 2003.

14. Hardy M., Conway M. La teoría del rol; perspectiva para los profesionales de la salud. Nueva York; 1978.

15. De von Bertalanffy, L. La teoría general de sistemas: fundamentos, desarrollo y aplicaciones. 5 ed. Petropolis: voces; 2010

16. Espina M. Problemas del cuidador y el afrontamiento del estrés. Prous: Barcelona. 1994.

17. Borrell F. Comunicar bien para dirigir mejor .Ediciones Gestión, Barcelona; 2002. 
18. Ceberio M. La buena comunicación. Las posibilidades de la interacción humana. Barcelona: ediciones Paidós Ibérica S. A; 2006.
19. Senge P. La quinta disciplina. Barcelona: Granica; 1992. 